\title{
Changes in Mass and Dimensions of Sunflower (Helianthus annuus L.) Achenes and Seeds Due to Carbonization ${ }^{1}$
}

\author{
Freek Braadbaart ${ }^{2}$ and Patti J. Wright ${ }^{3, *}$ \\ ${ }^{2}$ Department of Earth Sciences-Geochemistry, Faculty of Geosciences, Utrecht University, P.O. Box \\ 80021, 3058TA Utrecht, the Netherlands; e-mail: brabra@wxs.nl \\ ${ }^{3}$ Anthropology Department, University of Missouri-St. Louis, St. Louis, MO 63121, USA; e-mail: \\ pjwright@umsl.edu \\ *Corresponding author
}

\begin{abstract}
Changes in Mass and Dimensions of Sunflower (Helianthus annuus L.) Achenes and Seeds Due to Carbonization. When analyzing sunflower (Helianthus annuus L.) remains, which are often carbonized, archaeobotanists commonly differentiate between wild and domesticated achenes and seeds based on the measured length (L) and width (W) or the calculated index $L^{*} W$. Carbonization reduces the dimensions. To compensate for these reductions, archaeobotanists use a single correction factor proposed by Richard Yarnell (1978) for all cases. The use of a single correction factor can bias the reconstructed dimensions as carbonization is a highly variable process. The current study determines the relationship between carbonization and the dimensions of length and width. Measurements established that a decrease of $2.5-22.5 \%$ in achene length and $10-29 \%$ in achene width can occur, depending on temperature, heating rate, and variety. For seeds, temperature is of most importance, and shrinkage ranges from $0-27 \%$ for the length and from $0-20 \%$ for the width. These ranges make the use of a single correction factor problematic. A method is developed in which reflectance (an optical property applied in coal technology to determine coal rank) is used to measure the carbonization temperature, and in turn the shrinkage can be calculated. Subsequently, correction factors are calculated to reconstruct the original length and width. When applied to an assemblage of carbonized sunflower achenes, the newly developed method shows that the Yarnell single correction factor may bias the dimensions towards classifications of "wild" or "ruderal" forms of sunflower.
\end{abstract}

Key Words: Sunflower achenes and seeds, Helianthus annuus, carbonization, reflectance, paleoethnobotany.

Macrobotanical remains of fruits and seeds found in the archaeological record are essential to our understanding of human cultural developments. Carbonization is one of the processes by which these remains survive the physical and chemical decomposition associated with burial at an archaeological site. In this context, carbonization can be described as the exposure of fruits and seeds to any heat source in the absence of air. Subsequently, the heat or thermal energy is then transferred by radiation from the heat source to the plant tissues (Braadbaart et al. 2004a).

While carbonization can facilitate the preserva2007. tion of plant remains, it also can cause various distortions in the physical properties of the fruits and seeds which may impact their shapes and dimensions (Hopf 1955; van Zeist 1970; Kislev and Rosenzweig 1989; Smith and Jones 1990; Wright 1998, 2003). Because archaeobotanists often rely on lengths, widths, and diameters of the carbonized fruits and seeds to determine if a plant remain reflects a wild or a domesticated species, the distortions can impede their ability to measure and to reconstruct the precarbonized dimensions necessary for assessing domestication.

In North America, it is common to differentiate between wild and domesticated forms of sunflower (Helianthus annuus L.) based on the measured length and width or a calculated size index (Lentz et al. 2001). For sunflower, an $L^{*} W$ index 
is used in conjunction with a single correction factor (accounting for the shrinkage associated with carbonization) to estimate the original size of the achene or seed (Yarnell 1978). However, physical as well as chemical properties depend strongly on the variables that determine the carbonization process (Braadbaart and Bakels n.d.), and it can be expected that changes in the dimensions of the achenes and seeds will depend on these variables. In this study, two types of variables are recognized: (1) more general variables related to the heat source, and (2) more specific variables related to the samples under investigation.

Studies on various fruits and seeds show that their physical properties and chemical structure change as a function of the temperature and the time of exposure to the heat source (Braadbaart $2004 \mathrm{~b}$ ). The primary process that results from carbonization is the gradual conversion of the main constituents of the plant tissues (polysaccharides, protein, lipids, and lignin) into a range of aromatic moieties. Simultaneously, many volatiles are formed that cause a considerable mass loss and a corresponding shrinkage of the original material.

Braadbaart et al. (2007) assess the influence of carbonization on the chemical structure of a single variety (Arikara) of sunflower achenes and seeds. Results indicate that at $310^{\circ} \mathrm{C}$ the original constituents (polysaccharides, proteins, and lignin) are converted into aromatic compounds, and most lipids evaporate rather than carbonize. Between 370 and $400^{\circ} \mathrm{C}$, all the lipids have disappeared from the residues.

The current research expands upon the 2007 article. We have broadened our study to include two other varieties of sunflowers and focused this research on the physical changes in dimension that are critical to the evaluation of archaeological sunflower remains. In sum, we found that impacts of carbonization on mass and dimensions are a function of heat source and sample-related variables. In this article, we detail information about those interrelationships and present a method that can not only enhance our understanding of thermal exposure, but also can, with more precision, aid in correcting for carbonization.

\section{Samples and Methods}

\section{SAMPLES}

Modern sunflowers (Helianthus annuus L. var. Arikara) were grown by Wright in an experimental garden situated in St. Louis, Missouri, U.S.A.

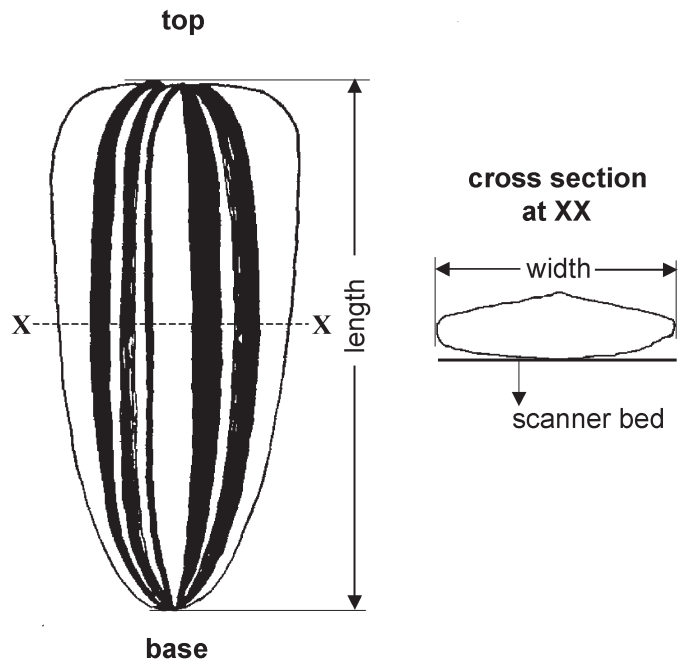

Fig. 1. Key to the measured dimensional features and the orientation of sunflower achenes on the scanner bed. For seeds the same procedure is followed.

Seeds were obtained from the North Central Regional Plant Introduction Station of the United States National Germplasm System. Initially, the variety, Arikara, was chosen based on conversations with Charles Heiser (personal communication 2004; Heiser 1953), who, along with Richard Yarnell, conducted seminal research in understanding the carbonization and domestication of the sunflower in North America. The Arikara achenes were harvested in the fall of 2004. To better assess the range of effects that occurs with carbonization, we expanded our experiments to include other varieties of sunflowers. In keeping with previous experiments conducted by Wright (2003), we chose the variety Hopi Black Dye. We also selected a third variety, Apache Brown. These latter two varieties were obtained in bulk from Native Seed SEARCH, a privately operated U.S. seed bank dedicated to the preservation to the preservation of Native American strains of crops. Combined, the three varieties represent a diverse range of sizes and shapes.

Because achenes as well as isolated seeds are recovered from archaeological contexts, we experimented with both forms. The seeds for the laboratory experiments were separated from achenes by manually removing the pericarp or hull. Lengths and widths of the total population $(n=100)$ were measured (Fig. 1), and masses were obtained of each variety. These data are summarized in Table 1 . In order to reduce the 
TABle 1. A. Length AND Width OF THE INVESTIGATEd SUNFLOWER ACHENES.

\begin{tabular}{llccc}
\hline \hline & & Arikara & Hopi Black Dye & Apache Brown \\
\hline Length $(\mathrm{mm})$ & Mean $(\mathrm{n}=100)$ & 11.95 & 10.30 & 11.51 \\
& S.D. & 1.04 & 0.74 & 0.67 \\
Width $(\mathrm{mm})$ & Degree of variation & $9.40-14.10$ & $8.55-12.04$ & $9.80-13.17$ \\
& Mean $(\mathrm{n}=100)$ & 6.53 & 4.85 & 8.30 \\
& S.D. & 0.95 & 0.81 & 0.81 \\
$95 \%$ conf. interval & Degree of variation & $4.38-9.40$ & $3.84-9.24$ & $5.91-10.48$ \\
$(\mathrm{n}=10)$ & length $(\mathrm{mm})$ & $11.31-12.60$ & $9.57-10.57$ & $11.13-11.97$ \\
& width $(\mathrm{mm})$ & $5.94-7.12$ & $6.18-7.2$ & $7.94-8.94$ \\
\hline
\end{tabular}

B. LENGTH AND WIDTH OF THE INVESTIGATED SUNFLOWER SEEDS.

\begin{tabular}{llccc}
\hline \hline & & Arikara & Hopi Black Dye & Apache Brown \\
\hline Length $(\mathrm{mm})$ & Mean $(\mathrm{n}=100)$ & 8.38 & 7.68 & 8.37 \\
& S.D. & 1.17 & 0.62 & 0.66 \\
Width $(\mathrm{mm})$ & Degree of variation & $5.69-10.37$ & $6.36-9.74$ & $7.20-10.02$ \\
& Mean $(\mathrm{n}=100)$ & 4.18 & 4.16 & 4.73 \\
& S.D. & 0.56 & 0.65 & 0.56 \\
$95 \%$ conf. interval & Degree of variation & $2.96-5.43$ & $2.84-5.86$ & $3.60-6.11$ \\
$(\mathrm{n}=10)$ & length $(\mathrm{mm})$ & $7.66-9.10$ & $7.30-8.06$ & $8.06-8.88$ \\
& width $(\mathrm{mm})$ & $3.82-4.55$ & $3.76-4.56$ & $4.38-5.08$ \\
\hline
\end{tabular}

C. Weight OF INVESTigated ACHENES AND SEEDS.

\begin{tabular}{cllcc}
\hline \hline & & Arikara & Hopi Black Dye & Apache Brown \\
\hline Mean mass of & Achene & $0.7780(100 \%)$ & $0.8850(100 \%)$ & $1.2051(100 \%)$ \\
samples of 10 & Seed & $0.4231(53.7 \%)$ & $0.3675(41.5 \%)$ & $0.4947(41.1 \%)$ \\
specimens $(\mathrm{gr})$ & Hull & $0.3649(46.3 \%)$ & $0.5175(58.5 \%)$ & $0.7104(58.9 \%)$ \\
\hline
\end{tabular}

size of the samples to be investigated, 95\% confidence intervals were calculated (Table 1). The results showed that for sunflower achenes and seeds, random samples of $\mathrm{n}=10$ are sufficient to fit the $95 \%$ confidence interval for length and width. Means of lengths and widths for each sample were used to investigate the influence of carbonization on changes in dimensions.

To illustrate the potentials of our method for reconstructing dimensions, we applied our method of reflectance on archaeological achenes. These achenes were derived from the Stelzer Site (23SC910), St. Charles County, Missouri (Harl and Wright 1994). These samples are referred to as "archaeological achenes or seeds."

\section{Reflectance}

The carbonization process and its governing variables, as well as the application of reflectance measurements, have been discussed extensively elsewhere (Braadbaart 2004b). Because they play an important role in this study, these phenomena will be briefly described. In particular, reflectance measured on carbonized organic material, in this case sunflower achenes and seeds, can be used to determine the temperature at which they have been carbonized. The main constituents of achenes are cellulose, lignin, proteins, and oil. With increasing temperatures, the oils evaporate, and the chemical structure of the other three constituents gradually changes into aromatic ring structures. These aromatic rings are more planar than their precursors and tend to align with each other, causing more light to reflect. Reflectance is measured through the optical properties, i.e., the refractive and absorption indices of the aromatic rings, and is defined as the percentage of vertically incident monochromatic light reflected 
from a highly polished surface of a sample calibrated against the light reflected from a standard of known reflectance. At temperatures of approximately $270^{\circ} \mathrm{C}$ and higher, the formation of multi-ring (3-5) aromatic structural units causes an increase in reflectance (Carr and Williamson 1989; Braadbaart 2004b). From about $440^{\circ} \mathrm{C}$, condensation and further molecular reorganization associated with the formation of large polyaromatic sheets further increases the reflectance. The dependence on chemical structure, which determines the optical properties, means that reflectance can be used as an indirect method for resolving differences in the chemical structure.

To determine reflectance $(\% \mathrm{Rr})$, the following procedures were followed. From each sample carbonized at a given temperature, three specimens were embedded in resin blocks and polished. For each specimen, 100 randomly performed reflectance readings were performed in order to obtain a statistically acceptable population. From that population, the mean reflectance of each specimen was calculated. Reflectance was measured under oil immersion at a wavelength of 546 $\mathrm{nm}$ using a Leitz motorized DMLA microscope equipped with a xyz-stage and a Basler video camera (Veld 2006). Preparation of polished blocks and reflectance measurements were performed according to standard methods defined in ISO 7404, Part 2 (1985), and ISO 7404, Part 5 (1994). The same set of procedures was followed to measure the reflectance of the archaeological specimens. The results were compared to the experimental samples to determine the carbonization regime and, in turn, to estimate the shrinkage of the archaeological specimens.

\section{Digital Imaging Analysis}

Digital imaging analysis was used to record dimensions (Braadbaart and van Bergen 2005). This technique offers an objective and quantitative method to extract digital images from fruits and seeds and their carbonized residues. These images can be used to measure dimensions of individual specimens and mathematically extract size and shape-related information. For the experiments, length and width of achenes and seeds were extracted from images in which each sample had been placed in the same orientation (Fig. 1) and measured by digital analysis.

The imaging hardware and software, and the image grabbing and analysis, have been described extensively in earlier studies, and the reader is re- ferred to the relevant publications (Braadbaart 2004b; Braadbaart and van Bergen 2005).

\section{The Carbonization Process and Laboratory Simulation}

Samples of sunflower achenes and seeds exposed to any heat source will absorb the heat or thermal energy that is transferred by radiation from the source to the samples. When this process occurs under conditions where air has free access, samples will burn and ash. Under reduced or anoxic conditions (i.e., the absence of air), the samples not only undergo a very different chemical conversion, but contrary to the burning process, their structure is often retained and may be recognized following recovery from archaeological contexts. This process is usually referred to as carbonization or charring. The absorption of the heat causes an increase in temperature of the samples, and the degree of change is dependent on heat source-related variables such as temperature and time of exposure. Heat transferred into an object by thermal radiation is a function of several components, including surface reflectivity, emissivity, conductivity, surface area, and geometric orientation, among others. This second group of variables, which also influences the change, is directly related to the properties of the sample and is referred to as the sample-related variables.

Increasing temperature will drive the chemical reactions that convert the main constituents of the achenes and seeds, polysaccharides (cellulose), proteins, and lignin, into a range of new, mostly aromatic, moieties, while most oils will evaporate (Braadbaart et al. 2007). These conversions are accompanied by the release of large amounts of volatiles that disappear into the external environment. One result is a mass loss that quickly increases to 60 or $70 \%$ from 250 to $370^{\circ} \mathrm{C}$, and reaches more than $80 \%$ at $600^{\circ} \mathrm{C}$. Simultaneously, the carbon content increases, hence the term "carbonization" (Braadbaart et al. 2007). In addition, the color of the achenes began to blacken at $290^{\circ} \mathrm{C}$. At higher temperatures, the color remains black, but other physical properties and the chemical structure change as a function of temperature and time. Accordingly, carbonization is a process that depends strongly on a number of variables.

In the current study, the influence of these variables on the physical and chemical properties of carbonized achenes and seeds is investigated by simulating the carbonization process. In the laboratory, samples were heated in a tube oven under 
a constant flow of nitrogen to produce anoxic conditions. Samples were heated to a variety of temperatures and times. More details about carbonization are described in Braadbaart (2004b) and embedded in the discussions below.

\section{Variables Determining the Carbonization Process of Sunflower Achenes and Seeds}

\section{Heat Source-Related Variables}

Temperature and the time of exposure are the most obvious heat source-related variables that determine the carbonization process. Loss in mass of the samples is a key feature associated with this process. In previous experiments with peas and wheat, Braadbaart (2004b) has shown that samples with an equal mass loss have an identical chemical structure. This important relationship exists because specimens absorb a similar amount of heat or thermal energy that drives the chemical reactions, and that, in turn, converts the main constituents of the specimens into a series of new moieties. For peas and wheat, as well as for sunflower achenes and seeds, these changes occur in two stages. At temperatures lower than $370^{\circ} \mathrm{C}$, or stage 1 , mass loss not only intensifies with higher temperature, but also with increasing time of exposure. This scenario implies that a sample that has attained a mass loss of $40 \%$ could be exposed to a heat source for seven days at $290^{\circ} \mathrm{C}$, but the same mass loss could also be reached by heating a sample for 120 minutes at $310^{\circ} \mathrm{C}$ or for nine minutes at $340^{\circ} \mathrm{C}$. In the second stage, with temperatures higher than $370^{\circ} \mathrm{C}$, and after a short initial time (maximum eight minutes), the mass loss remains constant for each temperature even when the time of exposure increases. In addition, the chemical structure does not change. As previously described, the reflectance measured on samples can be used as a proxy for the chemical structure. By measuring the reflectance on samples carbonized at temperatures higher than $370^{\circ} \mathrm{C}$, it is possible to determine the temperature at which achenes and seeds were carbonized, even if the time of exposure is unknown.

Above we suggest that temperature and time of exposure determine the carbonization process. However, one needs to consider "time" as the time needed to heat achenes and seeds from their ambient to their final temperature. This approach to time is determined by the heating rate or the increase of the temperature of the samples in degrees Celsius per unit of time $\left({ }^{\circ} \mathrm{C} \mathrm{min}^{-1}\right)$.
The heating rate depends on heat source and sample-related variables. The large number of variables that shape the carbonization process makes it difficult to study the influence of this process on achenes and seeds. To understand the process, it becomes necessary to isolate and limit the number of variables. Consideration of the conditions in which archaeological achenes and seeds may carbonize resulted in our selection of two kinds of heating conditions.

In the first scenario, we attempted to simulate conditions where samples come into direct and immediate contact with the heat source, for example, when a burning roof falls on stored sunflowers. For this simulation, achenes and seeds were introduced into a preheated tube oven and directly exposed to the prevailing temperature of the heat source. Thermocouples inserted within the samples measured the temperature within the grains during the whole experiment, and the results indicate that the samples attained the oven temperature in a relatively short time (Braadbaart et al. 2004a). For oven temperatures of 310 and $600^{\circ} \mathrm{C}$, this took 11 and 6 minutes, respectively, and corresponds to heating rates of 26 and $97^{\circ} \mathrm{C}$ $\min ^{-1}$. For the purpose of this study these values are designated as high heating rates (HHR).

A second condition was simulated in which samples are less directly and more slowly exposed to a heat source. In an archaeological context, one can think of seeds in a ceramic vessel situated close to or in an open fire or in the vicinity of a fire that has just started and still has to reach its final temperature. Under this scenario, the temperature of the sample will rise from an ambient temperature of around $20^{\circ} \mathrm{C}$, which is assumed to be the temperature before the fire existed, to its final temperature. To simulate these scenarios, the samples were placed in the tube oven that has reached this ambient temperature. Subsequently, the oven was set for the selected final temperature and heating rate. By selecting a heating time of around 120 minutes, the heating rates are much lower than the ones attained in a preheated oven, as mentioned above, and are designated as low heating rates (LHR).

\section{Sample-Related Variables}

Sample-related variables are directly related to the size and the chemical composition of the samples. However, variation in chemical composition associated with thermal properties is limited (Braadbaart et al. 2007), and it is, therefore, 
assumed that these variables are identical for the investigated varieties. In the case of sunflowers, size may differ according to the variety; consequently, three different varieties were investigated.

The oil and water content of uncarbonized achenes and seeds requires more intensive analysis. The quantity of free water present in sunflower achenes or seeds is converted into vapor that disappears into the external environment when they attain a temperature of $100^{\circ} \mathrm{C}$. The available heat is used only for this conversion. As a result, the temperature of the sample will remain stable until all the water has been removed. If heat is still available, the temperature will rise again, and the usual chemical reactions characteristic of the carbonization process will occur. A similar conversion, but at different temperatures, occurs for any oils present in the samples. In short, our experiments show that variation in water or oil content of uncarbonized achenes and seeds will not influence the chemical conversion of their other constituents, the polysaccharides, proteins, and lignin. This does not mean that the oil content could not influence mass loss or changes in dimensions.

\section{Carbonization and Change of Mass, Reflectance, and Dimensions}

\section{Selection of the Variables}

Carbonization experiments with sunflower achenes and seeds, variety Arikara, were performed at oven temperatures ranging from 160 to $700^{\circ} \mathrm{C}$. The samples were introduced into a preheated tube oven inducing carbonization at a HHR. The time of exposure of all the experiments was 60 minutes, which was considered sufficient based on earlier works (Braadbaart et al. 2007; Braadbaart and Bakels n.d.). These experiments afford results as a function of a range of temperatures. Only the variety Arikara was used for the HHR experiments. Subsequently, the influence on the carbonization process on more varieties and at different heating rates was investigated. Hopi Black Dye and Apache Brown, in addition to Arikara, were used.

The influence of a LHR was studied by introducing the samples into a tube oven with an ambient temperature of about $20^{\circ} \mathrm{C}$. Tests were performed on samples of seeds and achenes, each containing 10 specimens per variety. To reduce the number of tests for the additional experi- ments, three temperatures were selected: 310 , 440 , and $600^{\circ} \mathrm{C}$. The rationale for the selection of these specific temperatures is as follows. At $310^{\circ} \mathrm{C}$ the conversion of polysaccharides, lignin, and proteins, present in achenes or seeds, into aromatic moieties is almost completed. The conversion makes the resulting residues more resistant to attacks by microorganisms upon deposit into the soil, and the chances that this material will be recovered from archaeological sites are much greater compared to material that consists of starch and proteins. The temperature of $440^{\circ} \mathrm{C}$ was selected because the chemical structure, now consisting only of condensed aromatic moieties (the lipids are not present anymore), will not change at higher temperatures. However, the reflectance continues to increase. The temperature of $600^{\circ} \mathrm{C}$ was selected because it seems to be a maximum temperature that can be reached when samples are heated in an open fire.

To study the influence of the LHR, the samples were carbonized at the above temperatures in separate series of experiments. For each temperature, 120 minutes was allowed for the oven to reach the optimal temperature of 310,440 , and $600^{\circ} \mathrm{C}$. Accordingly, the heating rate varied from $2.4-4.8^{\circ} \mathrm{C} \mathrm{min}^{-1}$. After the desired temperatures were attained, the samples were kept at that level for another 60 minutes in order to compare the results to those obtained under the HHR regime for 60 minutes.

\section{Mass Loss of Achenes and Seeds}

Samples, each containing 10 achenes or seeds, were weighed before and after carbonization, in order to calculate the percentage of mass loss. A strong rate of mass loss was observed for both achenes and seeds carbonized in the range of 250 to $400^{\circ} \mathrm{C}$, after which the rate of mass loss slowly decreased with temperature (Fig. 2).

The main constituents of sunflower seeds are lipids (47-65 wt\%) and proteins (20-40 wt\%) (González Pérez 2003). Carbonization has different effects on each biopolymer (Braadbaart et al. 2007). Lipids will evaporate, and, at a temperature of $370^{\circ} \mathrm{C}$, they have mostly disappeared. At $400^{\circ} \mathrm{C}$ lipids are no longer recognized. Proteins react differently. At temperatures in the range of $150-250^{\circ} \mathrm{C}$, when water once again becomes available due to dehydration processes, the proteins will swell, causing an increase in dimensions. At temperatures exceeding $250^{\circ} \mathrm{C}$, the proteins will gradually convert into aromatic compounds. 

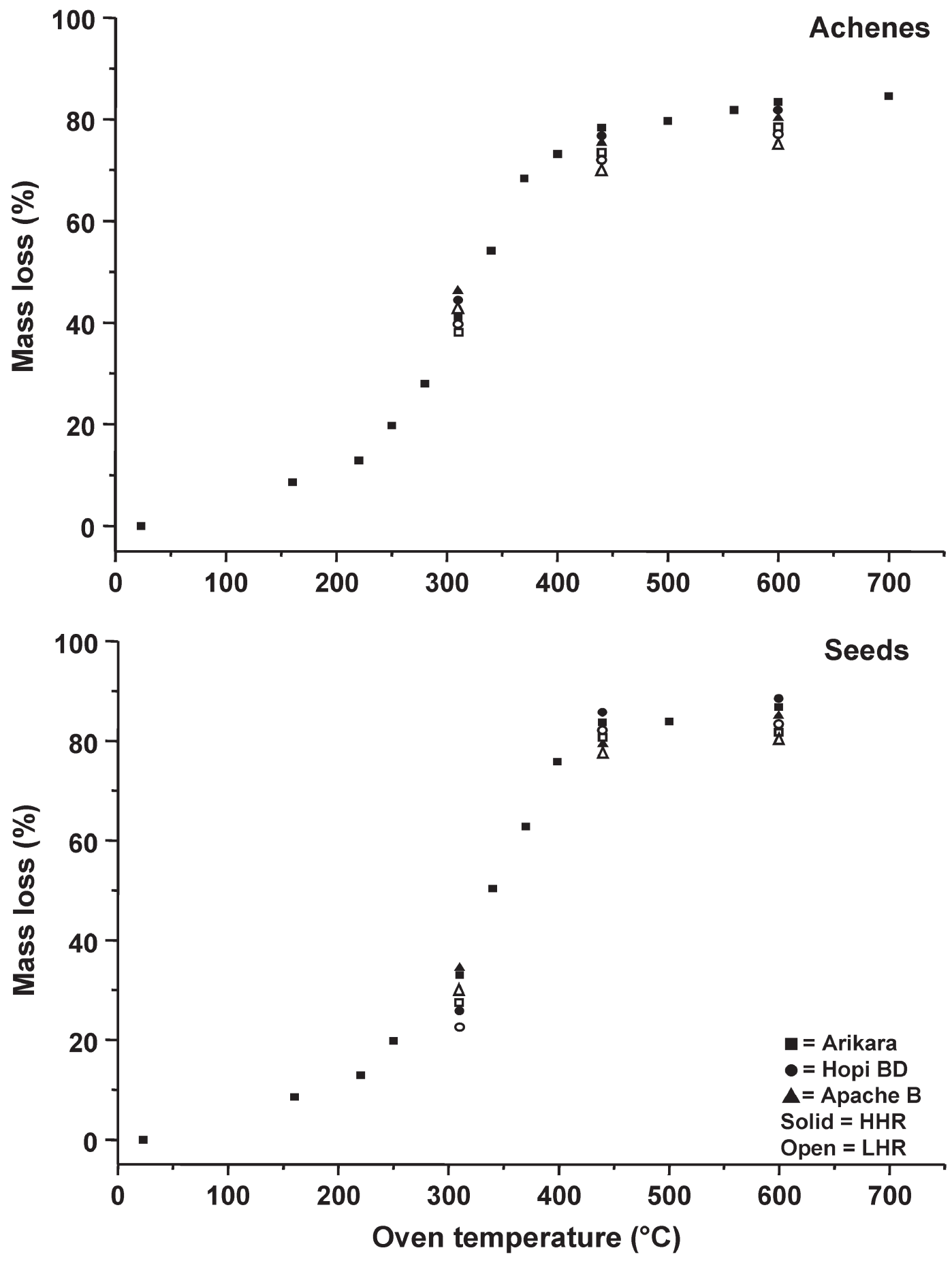

Fig. 2. Mass loss (\%) of sunflower achenes and seeds as a function of the temperature in ${ }^{\circ} \mathrm{C}$. Solid symbols carbonized at a high heating rate (HHR), open symbols at a low heating rate (LHR). 
From $310^{\circ} \mathrm{C}$ and higher, proteins are no longer observed. This process is accompanied by the release of many volatiles and, in turn, a strong mass loss occurs (Fig. 2). Between 310 and $440^{\circ} \mathrm{C}$, a further condensation of the aromatic compounds occurs with a loss of $\mathrm{CO}$ and $\mathrm{CO}_{2}$ that results in more mass loss (Braadbaart 2004b). At higher temperatures, a different type of conversion occurs, and the rate of mass loss decreases further.

The mass loss of seeds between 250 and $370^{\circ} \mathrm{C}$ is somewhat less than for achenes. With increasing temperature this difference gradually becomes smaller, and at temperatures above $400^{\circ} \mathrm{C}$, the mass loss of seeds exceeds that for achenes. These deviations can be attributed to the relative differences in the presence of oils and the fact that oils do not carbonize but rather evaporate. Mass loss occurs by evaporation of oils and chemical conversion of the other constituents. Seeds contain relatively more oils than achenes. Apparently in the lower temperature range, evaporation of oils is slower than chemical conversion. Consequently, seeds lose less material and have a lower mass loss. Once oils have evaporated, between 370 and $400^{\circ} \mathrm{C}$, the mass loss of the seeds becomes higher.

When compared to a HHR, the mass loss of achenes and seeds carbonized at a LHR is lower. The volatiles, which occur as a result of the carbonization process, traverse the residues on their way to the external environment, causing secondary reactions between these volatiles and the converting solids of seed and hull. In the case of a LHR, the time in which the volatiles reside within the heated specimens is longer compared to a HHR, and more time is available for secondary reactions. Thus more secondary moieties with identical chemical structure are formed. Consequently, more mass is formed and mass loss decreases.

\section{ReFLECTANCE}

The chemical structure of the constituents of the different sunflower varieties is similar. At temperatures where reflectance can be measured (higher than $270^{\circ} \mathrm{C}$ when aromatic ring structures start to form), the chemical structure of the carbonized sunflowers will be similar regardless of variety. To measure reflectance, the variety Arikara was selected. Reflectance rises slowly from 270 to $400^{\circ} \mathrm{C}$ (Fig. 3). Thereafter, it rises more rapidly. The S.D. of the measurements increases from 0.072 at $280^{\circ} \mathrm{C}$ to 0.23 at $600^{\circ} \mathrm{C}$.

When samples are carbonized at a HHR or

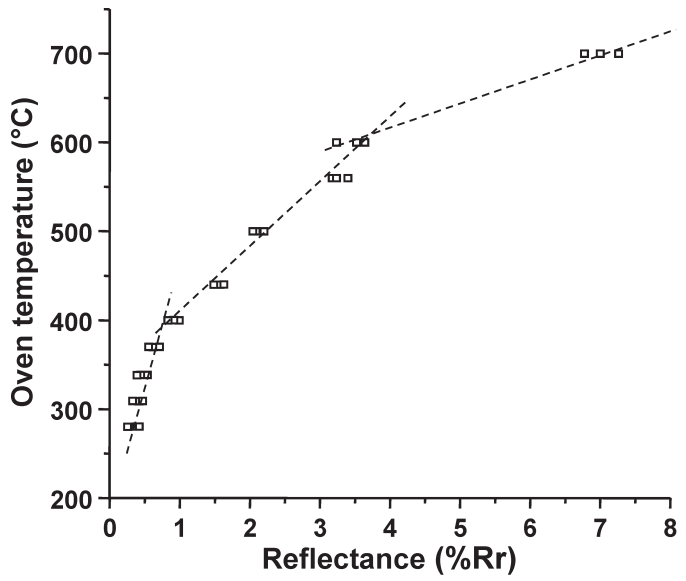

Fig. 3. Reflectance measurements (\%Rr) on sunflower achenes (var. Arikara), carbonized for $60 \mathrm{~min}$ utes at a high heating rate (HHR), as a function of the temperature in ${ }^{\circ} \mathrm{C} . \square=$ samples of achenes.

LHR at identical temperatures, the mass loss may vary, but the chemical structure is identical and, in turn, the reflectance will be identical. By measuring reflectance, the temperature at which achenes and seeds have been carbonized can be measured independent of the heating rate (Braadbaart and Bakels n.d.).

\section{Seeds: Changes in Length and Width}

Samples containing 10 seeds of the variety Arikara were prepared by manually removing the hulls from the achenes. Length (L) and width (W) of each seed were measured and their means calculated. These samples were carbonized for 60 minutes in the preheated tube oven (HHR) at each of the following temperatures: 160, 220, $250,310,340,370,400,440,500$, and $600^{\circ} \mathrm{C}$. After cooling, the specimens in the samples were remeasured and new means were calculated. Changes in the means of $\mathrm{L}$ and $\mathrm{W}$ are plotted as the percent shrinkage versus temperature (Fig. 4). Shrinkage is defined as the ratio of the untreated or original dimension minus the carbonized dimension to the untreated or original dimension, for example, for the width: $W_{\text {untreated }}-W_{\text {carb }} /$ $\mathrm{W}_{\text {untreated }} * 100 \%$.

At 160 and $220^{\circ} \mathrm{C}$, the Arikara seeds swelled, resulting in increased $\mathrm{L}$ and $\mathrm{W}$, which is shown as a negative shrinkage (Fig. 4). From $250^{\circ} \mathrm{C}$, L starts to shrink, but W remains almost equal to the width of the untreated seed until $370^{\circ} \mathrm{C}$. At 


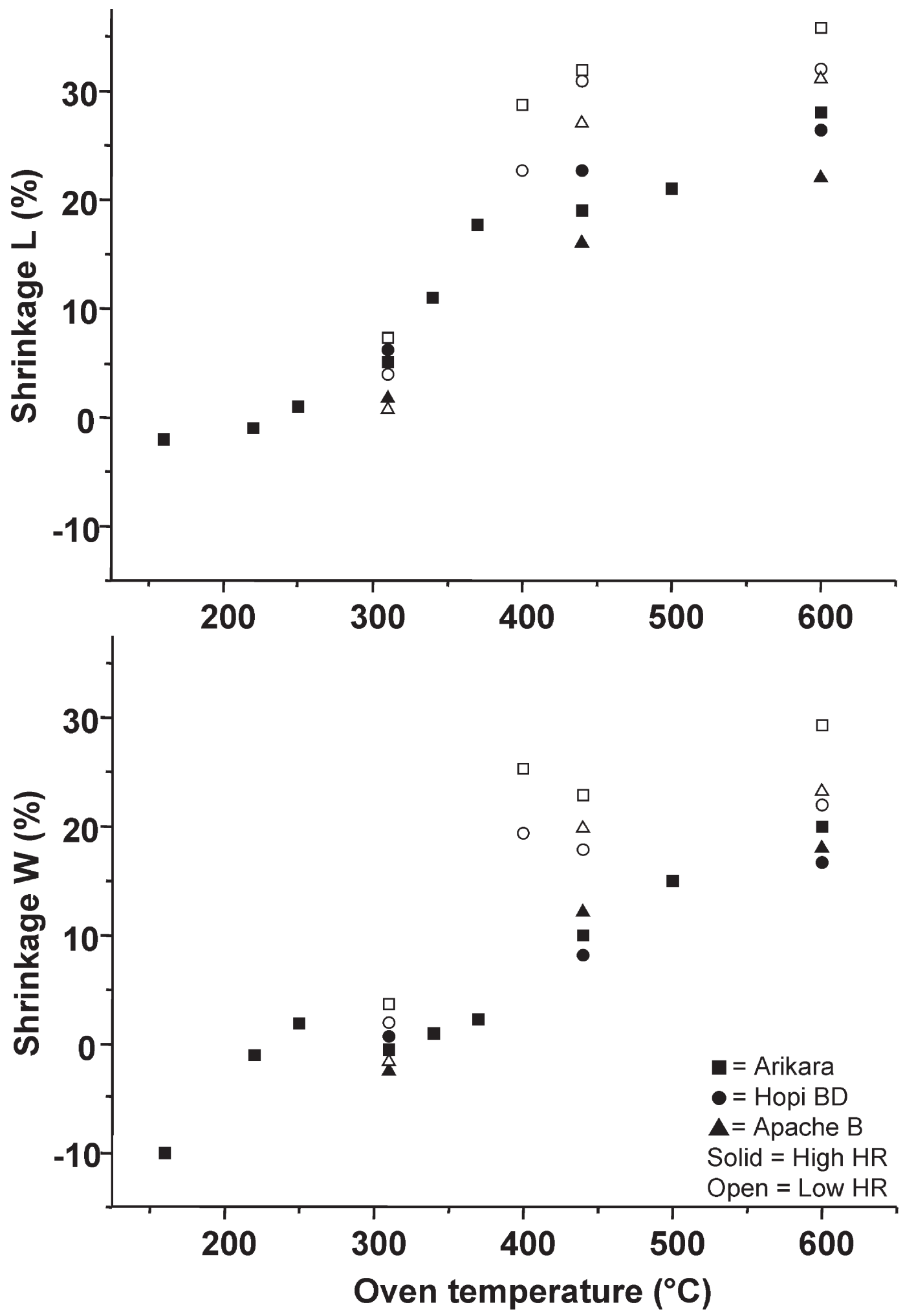

Fig. 4. Mean shrinkages of length (L) and width (W) of samples containing ten sunflower seeds of the indicated varieties as a function of the temperature in ${ }^{\circ} \mathrm{C}$. Solid symbols carbonized at a high heating rate (HHR), open symbols at a low heating rate (LHR). 
higher temperatures, W begins to shrink, eventually reaching a $20 \%$ reduction at $600^{\circ} \mathrm{C}$. Under these conditions L shrinks slowly from 250 to $310^{\circ} \mathrm{C}$, then shrinks more rapidly reaching an $18 \%$ reduction at $370^{\circ} \mathrm{C}$ and $28 \%$ at $600^{\circ} \mathrm{C}$.

Subsequently, samples of 10 seeds of the varieties Hopi Black Dye and Apache Brown were carbonized under similar conditions (HHR), and the shrinkages of $\mathrm{L}$ and $\mathrm{W}$ were calculated based on their sample means. The mean mass of the original Arikara seeds is higher than the seeds of the other two varieties, which points to a higher oil content. The results indicate that differences in shrinkage of $\mathrm{L}$ and $\mathrm{W}$ between the three varieties are not substantial, even when the oil content differs (Fig. 4).

In order to investigate the influence of the heating rate on the shrinkage of $\mathrm{L}$ and $\mathrm{W}$, the three varieties were carbonized at 310,440, and $600^{\circ} \mathrm{C}$ at a LHR. At temperatures higher than $310^{\circ} \mathrm{C}$, seeds of all three varieties carbonized at a LHR show a substantial greater shrinkage of $\mathrm{L}$ and W than when carbonized at a HHR (Fig. 4). The differences between the three varieties are still rather small. It is noted that the seeds carbonized under the latter conditions are rather distorted and fragile, but L and W are still measurable. One may wonder if these vulnerable residues will survive deposition into the soil and subsequent recovery by the archaeologist.

\section{Achenes: Changes in Length and Width}

Samples of 10 Arikara achenes were carbonized under similar conditions (HHR) as described for seeds. The shrinkages of $\mathrm{L}$ and $\mathrm{W}$ are plotted versus the temperature of the heat source (Fig. 5). From $160^{\circ} \mathrm{C}$, the shrinkage of $\mathrm{W}$ gradually increases to $13 \%$ at $310^{\circ} \mathrm{C}$, then more strongly to $23 \%$ at $340^{\circ} \mathrm{C}$. Thereafter it increases more slowly to $27 \%$ at $700^{\circ} \mathrm{C}$. The shrinkage of $\mathrm{L}$ persists at about $3 \%$ to $310^{\circ} \mathrm{C}$, then increases to $17 \%$ at $370^{\circ} \mathrm{C}$, and eventually rises to $22 \%$ at $700^{\circ} \mathrm{C}$.

Samples of the varieties Hopi Black Dye and Apache Brown were carbonized under similar conditions (HHR) and shrinkages calculated based on the sample means for L and W. The achenes of Hopi Black Dye show a trend similar to Arikara achenes, but the shrinkage is about 5\% less for both L and W. Uncarbonized Hopi Black Dye achenes are the smallest of the three varieties, and this difference in size might explain their relatively less shrinkage. However, uncar- bonized Arikara achenes are smaller than Apache Brown achenes, but their respective percent shrinkage does not substantially differ.

The influence of the heating rate on $\mathrm{L}$ and $\mathrm{W}$ of sunflower achenes was determined by carbonizing the three varieties at 310,440 , and $600^{\circ} \mathrm{C}$ at a LHR. For achenes, the results are different from those obtained for seeds. The differences among the varieties are rather small (Fig. 5).

\section{Properties of the Archaeological Achenes and Seeds}

\section{INTERNAL MORPHOLOGY}

The microphotograph of the polished cross section of the archaeological achene (Fig. 6a) show depressions (d) that are surrounded by light colored walls (w). It is very likely that these walls are the original cell walls, which have been polished to a flat surface. The SEM micrograph of the cross section of an achene of the variety Arikara, heated for 60 minutes at $370^{\circ} \mathrm{C}$ (Fig. $6 \mathrm{~b}$ ), is also characterized by depressions (d) surrounded by walls (w), but in this case the walls do not exhibit a flat surface. When comparing both figures, a similar cross section is observed; however, the polishing necessary to measuring reflectance resulted in a flattening of the superior walls of the archaeological achene.

\section{Reflectance and Chemical Structure}

The reflectance and chemical structure of the five archaeological achenes recovered from the Stelzer site were determined. The reflectance varied from 0.63 to $1.25 \% \mathrm{Rr}$, corresponding to temperatures of 365 and $420^{\circ} \mathrm{C}$, respectively. The differences in temperature are possible as each achene will not have been in the same position near or within the fire that caused the carbonization. Of great interest, the temperatures derived by reflectance fall in the range where the greatest variation in shrinkage occurs (Fig. 5). Also of significance, and as expected given the results of our experiments, oils are not present in the specimens carbonized at $400^{\circ} \mathrm{C}$ and higher.

\section{Reconstruction of the Original Dimensions}

\section{General}

Open fires, wherein the supply of air is limited due to a poor mixing of fuel and air (Albini 1993), are the commonly expected conditions producing carbonized plant remains at archaeo- 

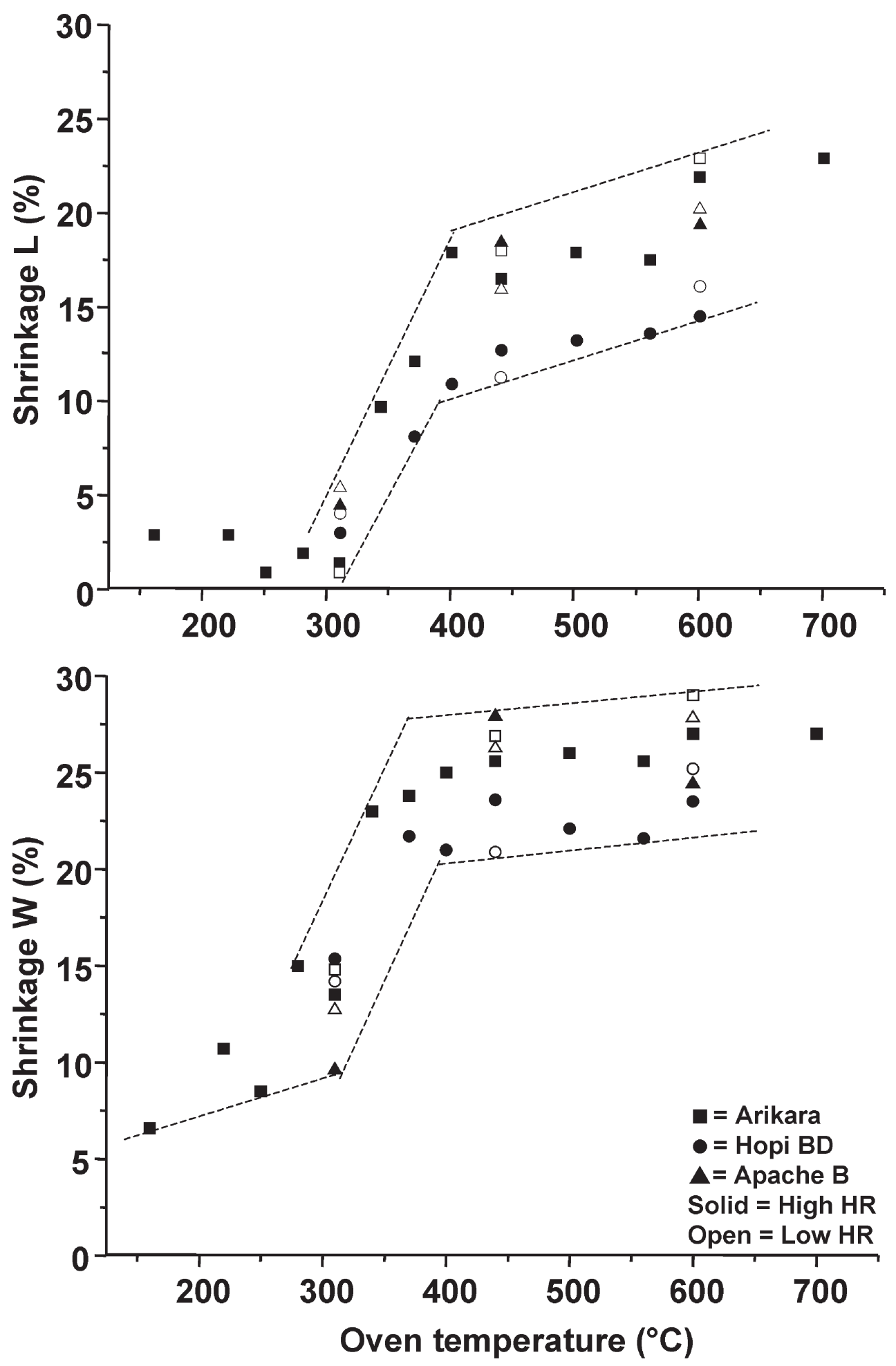

Fig. 5. Mean shrinkages of length (L) and width (W) of samples containing ten sunflower achenes of the indicated varieties as a function of the temperature in ${ }^{\circ} \mathrm{C}$. Solid symbols carbonized at a high heating rate (HHR), open symbols at a low heating rate (LHR). Dashed lines indicate the upper and lower limits of the mean shrinkages. 
a

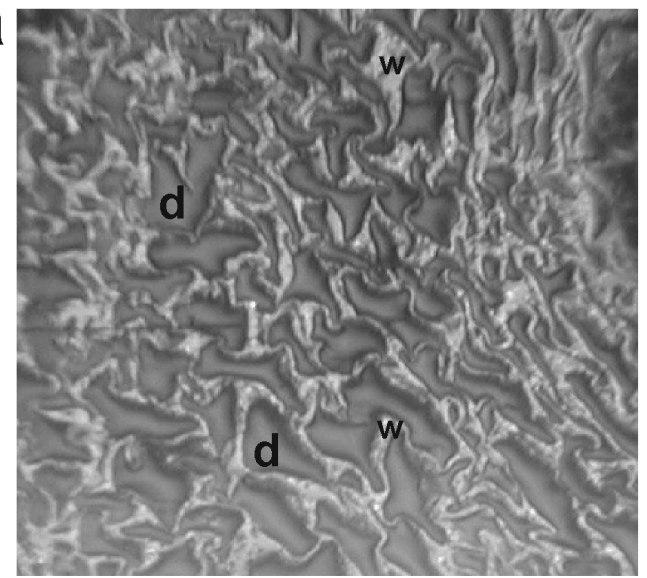

$100 \mu \mathrm{m}$ b

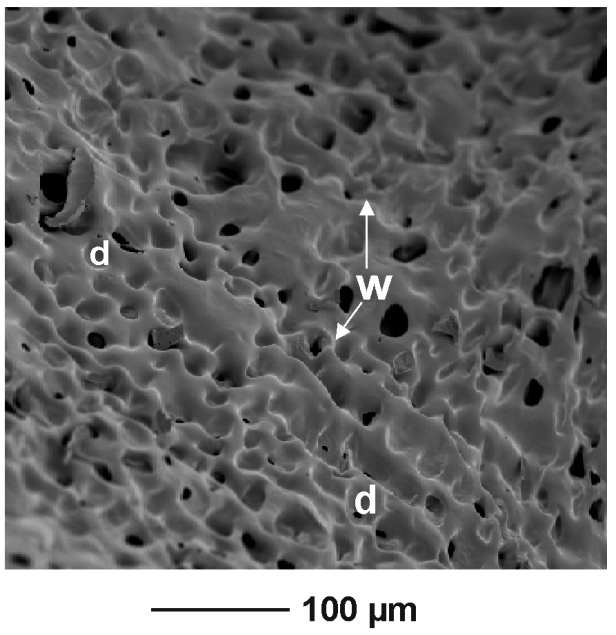

Fig. 6. Micrographs of the internal structure of sunflower achenes: (a) polished cross section of the resinembedded archaeological achene, and (b) SEM cross section of an achene (var. Arikara) carbonized for 60 minutes at $370{ }^{\circ} \mathrm{C} . \mathrm{d}=$ depression and $\mathrm{w}=$ wall.

logical sites in temperate open-air settings. To enhance analysis, it becomes important to understand the carbonization process. Accordingly, carbonization experiments on modern plant tissues under well-controlled conditions in a laboratory were conducted and compared to experiments with similar propagules under less controlled conditions in an open fire (Braadbaart 2004b). The results of the experiments under both types of conditions show that the processes governing carbonization are similar for any type of heat source. Therefore, results obtained from experiments carried out in the laboratory can also be used for carbonized specimens recovered from the archaeological record. This conclusion is important and affords a better understanding of how archaeological remains have obtained the characteristics that today's researchers observe.

The difference in temperature between a heat source and the achenes and seeds causes a transfer of heat by radiation to these samples; the temperature of the samples will increase until it has reached the temperature of the heat source. In the case of oil-containing seeds, the increasing temperature will cause the evaporation of the lipids and drive the reactions causing the chemical conversion of polysaccharides, proteins, and lignin, the other main constituents of the samples. It is these reactions which result in the losses of mass noted for the carbonized samples (Braadbaart et al. 2007). Consideration of these factors provides methods that make possible the reconstruction of the original dimensions of carbonized sunflower achenes and seeds recovered from an archaeological site.

The results of the present investigation on three varieties of sunflower achenes and seeds under different carbonization conditions show that temperature, heating rate, and variety cause differences in shrinkage of lengths and widths, varying according to data presented in Figures 4 and 5. As depicted in these figures, an important trend is observed that corresponds with the mass loss of the samples as a function of the temperature (Fig. 2). This trend is especially well noted in the case of achenes. It is possible to ascertain upper and lower limits of shrinkage (note the dashed lines in Fig. 5) that describe the shrinkage as a function of the temperature. By measuring the reflectance, it becomes possible to determine the temperature at which carbonization occurred, and by comparing the reflectance data to the background data achieved by the experiments, upper and lower percentages of shrinkage can be determined for archaeological specimens. Although achenes and seeds show more or less a similar behavior, certain differences are observed that require a separate discussion.

\section{SEEDS}

The cells of the seeds contain oil as well as protein (Braadbaart et al. 2007). No other biomolecules are present, except those that constitute the 
cell walls. At $310^{\circ} \mathrm{C}$, the mass loss of the seeds reaches $30 \%$, but hardly any shrinkage of $\mathrm{L}$ and $\mathrm{W}$ is observed (Fig. 2 and 4). The width does not shrink until $370^{\circ} \mathrm{C}$, when the bulk of the oil is evaporated. These results point to an evaporation of oil from the cells between 310 and $370^{\circ} \mathrm{C}$; during the intervals, the dimensions of the seeds remain unchanged because the oil inhibits the shrinkage of the cells. Thus only a gradual increase in mass loss is measured, while the shrinkage of $\mathrm{L}$ and $\mathrm{W}$ is limited. Once the oils have completely disappeared, between 370 and $400^{\circ} \mathrm{C}$, the amount of shrinkage increases.

Little difference in shrinkage is observed between the varieties when the samples are carbonized at a HHR for all investigated temperatures. Under a LHR regime to temperatures of $310^{\circ} \mathrm{C}$, the percentage shrinkage of the seeds is identical to seeds carbonized at a HHR. But at higher temperatures, the shrinkage of LHR seeds is much higher than that for HHR seeds. Figure 7 illustrates the results. In the figure, the lowest levels of shrinkage for the three varieties reflect seeds carbonized at a HHR. Their shrinkage forms a nearly straight line (Fig. 7). Beginning at $310^{\circ} \mathrm{C}$, the upper range of shrinkage reflects those seeds that were carbonized at a LHR. It should be noted that the LHR seeds are greatly distorted and fragile and are not likely to survive burial and recovery from archaeological contexts. It initially appears that slower heating causes a higher percentage of shrinkage than quicker heating. However, we suggest that it is not the rate of heating but the time of exposure to the heat source that explains the results. At LHR the seeds remained for three hours in the oven, while at a HHR they spent only one hour in the oven. The relationship with time is supported by previous experiments by Wright $(1998,2003)$.

Carbonized seeds are frequently found together with pieces of carbonized broken hull or with pieces of hull still stuck to the seed. Apparently seeds have been carbonized within the hulls, and after deposition or during recovery activities, mechanical forces caused the hulls to break. However, the current experiments reflect seeds carbonized after the removal of the hull. To investigate the influence of the presence of a hull, whole achenes were carbonized. Subsequently the hulls were carefully removed and the seeds measured to calculate the shrinkage. For this purpose, four samples were used: two carbonized at $440^{\circ} \mathrm{C}$ and two at $600^{\circ} \mathrm{C}$, all at a LHR. The results indi- cate that the shrinkage of the seeds is a function of the presence or absence of a hull at a HHR (Fig. 7). Moreover, a linear relationship with a strong positive correlation for both $\mathrm{L}$ and $\mathrm{W}$ exists. When reflectance is measured and plotted in Fig. 7 , the shrinkage can be measured and the original dimensions reconstructed.

\section{Achenes}

The rate of shrinkage of achenes, as a function of the temperature, corresponds with the rate of mass loss: a strong increase in shrinkage is observed from 250 to $370^{\circ} \mathrm{C}$, and thereafter the shrinkage increases more gradually (Fig. 5). In the lower temperature range where there is much shrinkage, the differences between the varieties and the heating rates are rather small. It is noted that seeds behave in a different way. In temperature ranges greater than ca. 370 to $400^{\circ} \mathrm{C}$, the lower limit of shrinkage is represented by carbonized Hopi Black Dye achenes, which are the smallest specimens of the three varieties. The upper limit in this temperature range consists of Arikara and Apaches Brown achenes.

\section{Archaeological Interpretations AND Reconstruction of the Dimensions}

To illustrate how the original dimension can be reconstructed from the dimensions after carbonization, the archaeological achenes recovered from a site in Missouri are used. The results are summarized in Table 2. On each sample the reflectance $(\% \mathrm{Rr})$ was measured. By plotting the reflectance in Fig. 3, the temperature at which a sample has been carbonized can be measured. Concurrently the temperature of each sample is plotted as a vertical line in Fig. 5, and the range of shrinkages can be measured at the intersection of each line with the upper and lower limit of $\mathrm{L}$ and W. The shrinkage for $\mathrm{L}$ varies between 7.5 and $19 \%$ and for W between 16.5 and 29\%. To reconstruct the original $\mathrm{L}$ and $\mathrm{W}$, the correction factor, $100 /(100-\%$ shrinkage $)$, has to be calculated. For $\mathrm{L}$ this factor ranges between 1.08 and 1.23, and for W between 1.20-1.41 (Table 3). By multiplying the correction factors with the actual $\mathrm{L}$ and $\mathrm{W}$ of each sample, the original $\mathrm{L}$ and $\mathrm{W}$ is reconstructed. The original length and width is also reconstructed by using Yarnell's correction factors: 1.11 for lengths and 1.27 for widths. It is important to note that for the five archaeological achenes, the latter correction factors produce low values for the uncarbonized dimensions 

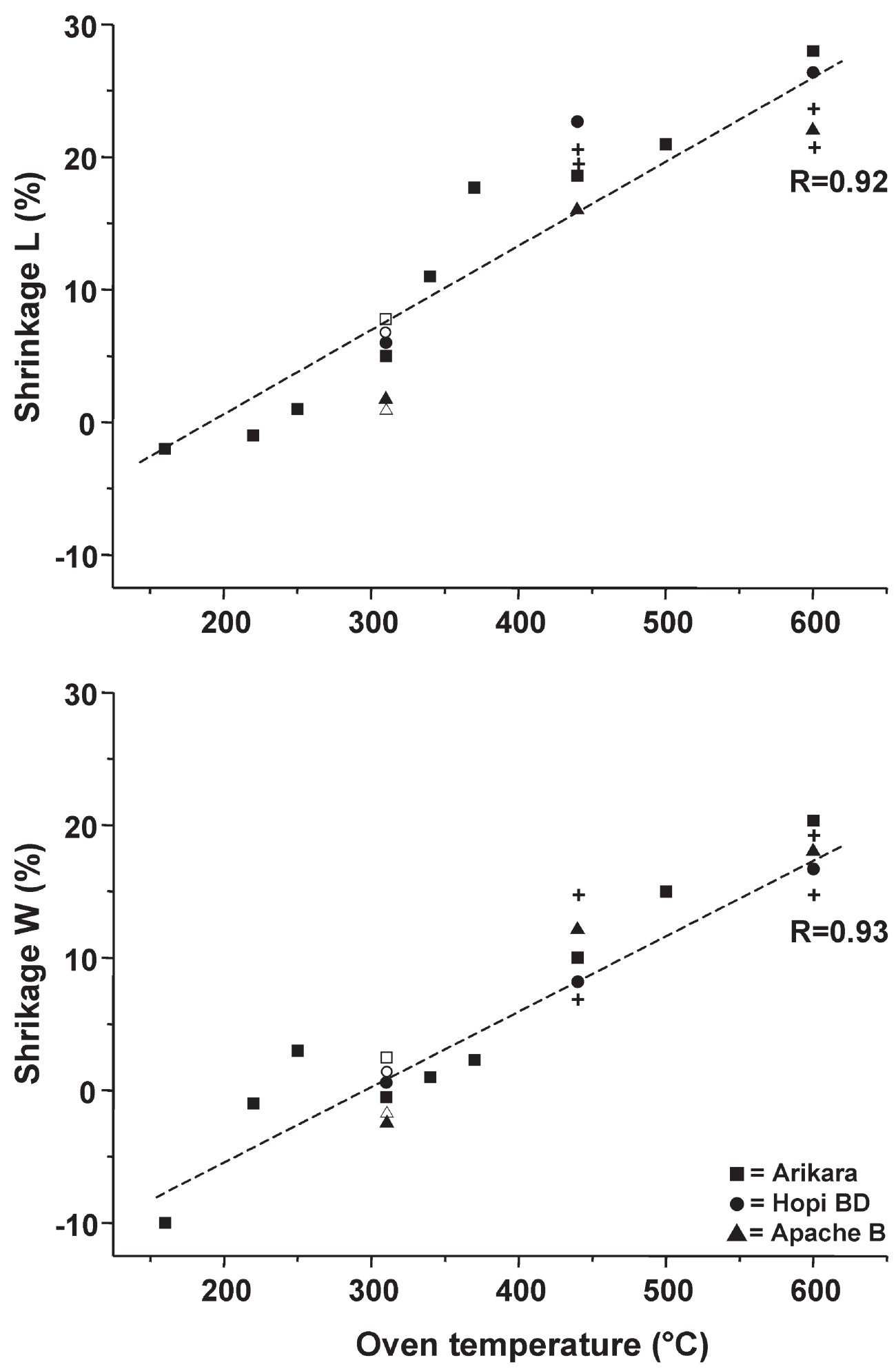

Fig. 7. Relationships between mean shrinkage of length (L) and width (W) of seeds of the three indicated varieties and the temperature in ${ }^{\circ} \mathrm{C}$. The solid and open symbols represent high heating and low heating rates, respectively, and are carbonized after removal of the hull. Crosses $(+)$ represent seeds carbonized in the hull at a low heating rate. 
TABle 2. Results of THE DETERMINATION OF REFLECTANCE, CARBONIZATION TEMPERATURE, SHRINKAGES, AND CORRECTION FACTORS FOR LENGTH (L) AND WIDTH (W) OF FIVE ARCHAEOLOGICAL ACHENES.

\begin{tabular}{lcccccc}
\hline \hline $\begin{array}{c}\text { Sample } \\
\text { No. }\end{array}$ & $\begin{array}{c}\text { Reflectance } \\
(\% \mathrm{Rr})\end{array}$ & $\begin{array}{c}\text { Temp. } \\
\left({ }^{\circ} \mathrm{C}\right)\end{array}$ & $\begin{array}{c}\text { Shrinkage } \\
\text { range } \\
\mathrm{L}(\%)\end{array}$ & $\begin{array}{c}\text { Correction } \\
\text { factors } \\
\mathrm{L}\end{array}$ & $\begin{array}{c}\text { Shrinkage } \\
\text { range } \\
\text { W (\%) }\end{array}$ & $\begin{array}{c}\text { Correction } \\
\text { factors } \\
\text { W }\end{array}$ \\
\hline 1 & 0.63 & 365 & $7.5-14.5$ & $1.08-1.17$ & $16.5-28$ & $1.20-1.39$ \\
2 & 0.63 & 365 & $7.5-14.5$ & $1.08-1.17$ & $16.5-28$ & $1.20-1.39$ \\
3 & 0.85 & 395 & $10-18.5$ & $1.11-1.23$ & $21-28.5$ & $1.27-1.40$ \\
4 & 0.95 & 405 & $10-18.5$ & $1.11-1.23$ & $21-28.5$ & $1.27-1.40$ \\
5 & 1.25 & 420 & $11-19$ & $1.12-1.23$ & $21.5-29$ & $1.27-1.41$ \\
\hline
\end{tabular}

TAble 3. Reconstruction of the original Length (L) AND Width (W) OF Five ARChaEOlOgical ACHENES APPLYING CORRECTION FACTORS FROM THIS STUDY AND YARNELL* (1978).

\begin{tabular}{lcccccc}
\hline \hline Sample No. & Actual L $(\mathrm{mm})$ & $\begin{array}{c}\text { Original } \\
\text { this study } \\
(\mathrm{mm})\end{array}$ & $\begin{array}{c}\text { Original L } \\
\text { Yarnell* } \\
(\mathrm{mm})\end{array}$ & $\begin{array}{c}\text { Actual W } \\
(\mathrm{mm})\end{array}$ & $\begin{array}{c}\text { Original W } \\
\text { this study } \\
(\mathrm{mm})\end{array}$ & $\begin{array}{c}\text { Original W } \\
\text { Yarnell* }(\mathrm{mm})\end{array}$ \\
\hline 1 & 5.14 & $5.55-6.01$ & 5.71 & 9.96 & $11.95-13.84$ & 12.65 \\
2 & 5.07 & $5.48-5.93$ & 5.63 & 12.00 & $14.40-16.68$ & 15.24 \\
3 & 5.24 & $5.82-6.45$ & 5.82 & 10.82 & $13.74-15.15$ & 13.74 \\
4 & 5.95 & $6.60-7.32$ & 6.60 & 10.14 & $12.88-14.20$ & 12.88 \\
5 & 6.08 & $6.81-7.48$ & 6.75 & 10.46 & $13.28-14.75$ & 13.28 \\
\hline
\end{tabular}

* Correction factor for $\mathrm{L}=1.11$ and $\mathrm{W}=1.27$.

\section{Consequences for Archaeological Research}

In 2001, while arguing for the domestication of sunflowers in Mesoamerica, Lentz et al. called into question the use of measurement as a means to distinguish domesticated versus wild forms of sunflower. The measurement scheme (and correction factor) referred to by Lentz et al. (2001) was instituted by Richard Yarnell. In his seminal article, "Domestication of Sunflower and Sumpweed in Eastern North America," Yarnell (1978:296) says, "In order to convert measurements of carbonized sunflower seeds and achenes to estimates of original achene size, it is necessary to increase achene length and width by $11 \%$ and $27 \%$ respectively, in accordance, with results obtained by Heiser (1953) ..."

Yarnell's correction factor became a standard for those researching the domestication of sunflower in North America. One could increase the achene length and width as prescribed and then compare the results to Table 1 of Yarnell's 1978 text. There Yarnell indicates that a $\mathrm{L}$ and $\mathrm{W}$ range of 3.0-5.5 $\times$ ? (W) is suggestive of a wild form of sunflower; $4.0-7.0 \times$ ? (W) is suggestive of a ruderal form; and $6.3-20+\times 3.2-1.2+$ is suggestive of a cultigen. His Table 1 also contains a series of corrected lengths and widths from archaeological achenes that had been derived from Late Archaic through Mississippian period deposits.

Since Yarnell's article, experiments such as Braadbaart (2004b), Smith and Jones (1990), Wilson (1984), and Wright (2003) have researched the effects of carbonization on a diverse range of seeds. The current experiment focused on sunflower. Experiments were conducted that demonstrate that a decrease of $2.5-22.5 \%$ in achene length and $10-29 \%$ in achene width can occur, depending on the heating regime and the variety used (Fig. 5). These figures are based on the assumption that the recovered specimens were carbonized between 310 and $600^{\circ} \mathrm{C}$. Correction factors can range from 1.03-1.29 for lengths and 1.11-1.41 for widths. We did not include the correction factors for temperatures below $310^{\circ} \mathrm{C}$ as these samples still contain sugars and proteins, and their chances to survive microbial attack in the soil are rather small.

In general, our correction factors contrast with Yarnell's single correction factors: 1.27 for widths and 1.11 for lengths. For the sake of argument in Table 4, we present the mean LW as calculated by 
Table 4. Mean LW based on Correction FACTORS FROM TABLE 1 OF YARNELl (1978) COMPARED TO CORRECTION FACTORS AS CALCULATED IN THIS STUDY.

\begin{tabular}{lcc}
\hline \hline Sites & $\begin{array}{c}\text { Mean LW } \\
\text { from Table 1, } \\
\text { Yarnell (1978) }\end{array}$ & $\begin{array}{c}\text { Range of mean LW } \\
\text { based on this study } \\
\text { (see text) }\end{array}$ \\
\hline $\begin{array}{l}\text { Late Archaic to Early } \\
\quad \text { Woodland }\end{array}$ & & \\
Higgs, TN & 24 & $20-31$ \\
Salts Cave J4: 10-11 & 18 & $15-24$ \\
Salts Cave J4: 5-8 & 24 & $20-31$ \\
Salts Cave J4: 4 & 25 & $23-33$ \\
Mammoth Cave-Nelson & 49 & $40-63$ \\
Middle to early Late & & \\
$\quad$ Woodland & & \\
Owl Hollow, TN & 34 & $28-44$ \\
Boyd, MS & 25 & $20-32$ \\
Mississippian & & \\
Great Oasis, IA & & \\
Wilford, MS & 56 & $46-72$ \\
Steed Kisker, MO & 41 & $35-53$ \\
Paul McCulloch, MO & 58 & $47-75$ \\
Turner-Snodgrass, MO & 82 & $66-106$ \\
Campbell, I., OH & 76 & $61-98$ \\
Cramer, OH & 78 & $64-101$ \\
\hline & 78 & $64-101$ \\
\hline
\end{tabular}

Yarnell (1978:Table 1) for a variety of Eastern Woodland sunflower achenes, and the range of mean LWs for these archaeological achenes based on our experiments. The comparison shows that Yarnell's mean LW produce conservative to moderate corrections. Accordingly, when comparing the mean LW or mean lengths and widths of an archaeological assemblage to the modern measurements, the archaeological assemblage could be classified as "wild" or "ruderal" when, in fact, it represents a "cultigen." While Yarnell's correction factors have been useful in identifying trends in achene and seed changes that can be linked to domestication, it is important to note that his correction factors reflect rather conservative estimates.

The problem in interpreting sunflower remains may not be measuring per se but rather the use of a single correction factor (viz., increasing achene length and width by $11 \%$ and $27 \%$, respectively) for all achenes and seeds. If one considers that variation in size is dependent on achene development and the variety of sunflower (Nelson 2002) and couples this understanding with variation in size as a result of heating, a single correction factor can grossly bias the interpretation. We argue that looking at ranges of large assemblages or caches provides a more realistic basis for interpretations for subsistence strategy. In addition, reflectance can control for the heating regime, and provides a corrected size range that is more specific in correcting for heating regime variables. Improvements in data analysis offered by this study can enhance our abilities to reconstruct prehistoric subsistence strategies and to understand interactions of crops and weeds.

\section{Summary}

It is understood that the carbonization of sunflower achenes and seeds has become increasingly significant given recent discussions in the literature about the origins of sunflower domestication. Lentz et al. (2001) call into question the use of measurements and corrections factors such as those posited by Yarnell (1978). The former (2001:372) aptly suggest that "carbonization is a highly variable process dependent on the temperature of the fire, exposure time, and moisture within the plant tissue."

Our experiment not only provides data to support Lentz's suggestion, but also provides a means to compensate for most of the variables associated with carbonization. Temperature, heating rate, and variety determine the shrinkage of achenes and seeds as a result of the chemical conversion caused by heating under anoxic conditions. By measuring the reflectance, the temperature at which the carbonization occurred can be calculated. The next step is the calculation of the shrinkages and the accompanying correction factors to reconstruct the original dimensions of achenes and seeds. Rather than abandon correction factors based on carbonization, we recommend testing the reflectance of archaeological seeds or achenes as a means to reconstruct their noncarbonized dimensions. As a caution, we acknowledge that the sunflower varieties recovered from archaeological sites may belong to unknown taxa or may have been distorted in ways that are unknown.

It is important to note that reflectance has applications beyond discussions of sunflower domestication. For example, in Europe, differentiating species and varieties of carbonized wheat grains (Triticum L.) based solely on the measured dimensions poses problems (Hillman et al. 1996; Jacomet 1987). Experiments involving the heating of three species of wheat have shown that the initial difference in the ratio of length to width among the three species gradually disappears with 
increasing temperature (Braadbaart and van Bergen 2005). Accordingly, the use of reflectance can be broadly applied to a variety of plants and investigations and interpretations that hinge on measurements of carbonized remains.

\section{Acknowledgments}

Technical assistance with scanning electron microscopy (SEM) by Dr. W. de Priester (Clusius Laboratory, Leiden University, the Netherlands) is gratefully acknowledged. We thank the anonymous reviewers for their insightful comments, which made this a better and more accurate paper.

\section{Literature Cited}

Albini, F. A. 1993. Dynamics and modeling of vegetation fires: Observations. Pages 39-52 in P. J. Crutzen and J. G. Goldammer, eds. Fire in the environment: The ecological, atmospheric and climatic importance of vegetation fires. Wiley, Chichester, U.K.

Braadbaart, F., P. J. Wright, J. van der Horst, and J. J. Boon. 2007. A laboratory simulation of the carbonization of sunflower achenes and seeds. Journal of Analytical and Applied Pyrolysis 78:316-327.

_ J. Jan der Horst, J. J. Boon, and P. F. van Bergen. 2004a. Laboratory simulations of the transformation of emmer wheat as a result of heating: The change of the physical, bulk chemical and molecular composition. Journal of Thermal Analysis and Calorimetry 77:957-973.

2004b. Carbonization of peas and wheat-A window into the past. University of Leiden, Leiden, The Netherlands.

— , and P. F. van Bergen. 2005. Digital imaging analysis of size and shape of wheat and pea upon heating under anoxic conditions as a function of the temperature. Vegetation History and Archaeobotany $14: 67-75$.

— morphological changes of modern dehusked and husked emmer and bread wheat grains (submitted).

Carr, A. D., and J. E. Williamson. 1989. The relationship between aromaticity, vitrinite reflectance and maceral composition: Implications for the use of vitrinite reflectance as a maturation parameter. Advances in Organic Geochemistry 16:313-323.

González Pérez, S. 2003. Physico-chemical and functional properties of sunflower proteins, University of Wageningen, Wageningen, The Netherlands.

Harl, Joseph L., and Patti J. Wright. 1994. Data recovery investigations at the Stelzer Site (23SC910), St. Charles County, Missouri. Paleothnobotanical Analysis, Research Report \#191, Department of Anthropology, University of Missouri, St. Louis.

Heiser, C. B. 1953. The archaeological record of cultivated sunflower with remarks concerning the origin of Indian agriculture in eastern North America. Unpublished manuscript on file at the Archaeological Laboratory, University of Missouri, St. Louis. Hillman, G. C., S. Mason, D. de Moulins, and M. Nesbitt. 1996. Identification of archaeological remains of wheat: The 1992 London workshop. Circaea 12:195-209.

Hopf, M. 1955. Formveränderungen von Getreidekörnern beim Verkohlen. Berichte der Deutschen Botanischen Gesellschaft 68:191-193.

International Standard ISO 7404-2. 1985. Methods for the petrographic analysis of bituminous coal and anthracite. Part 2: Method of preparing coal samples. Ref. no. ISO 7404-2:1985(E).

International Standard ISO 7404-5. 1994. Methods for the petrographic analysis of bituminous coal and anthracite. Part 5: Method of determining microscopically the reflectance of "vitrinite." Ref. no. ISO 7404-5:1994(E).

Jacomet, S. 1987. Prähistorische Getreide Fünde: Eine Anleitung zur Bestimmung Prähistorische Gerstenund Weizenfunde. Botanishes Institut der Universität Basel, Basel, Switzerland.

Kislev, M. E., and S. Rosenzweig. 1989. Influence of experimental charring on seed dimensions of pulses. Acta Interdisciplinaria Archaeologica 7:143157.

Lentz, D. L., M. E. D. Pohl, K. O. Pope, and A. R. Wyatt. 2001. Prehistoric sunflower (Helianthus annuus L.) domestication in Mexico. Economic Botany 55:370-376.

Nelson, Stuart O. 2002. Dimensional and density data and relationships for seeds of agricultural crops. Seed Technology 24:76-88.

Smith, H., and G. Jones. 1990. Experiments on the effects of charring of cultivated grape seeds. Journal of Archaeological Science 17:317-327.

van Zeist, W. 1970. Prehistoric and early historic food plants in the Netherlands. Palaeohistoria 14:41-173.

Veld, H. 2006. Personal communication. www.tno.nl.

Wilson, D. G. 1984. The carbonization of weed seeds and their representation in the macrofossil assemblages. Pages 199-206 in W. van Zeist and W. A. Casparie, eds. Plants and ancient man: Studies in palaeoethnobotany. A. A. Balkema, Rotterdam, The Netherlands.

Wright, P. J. 1998. The making of the carbonized macrobotanical record. Washington University, St. Louis, MO.

- 2003. Preservation or destruction of plant remains by carbonization? Journal of Archaeological Science 30:577-583.

Yarnell, Richard A. 1978. Domestication of sunflower and sumpweed in eastern North America. Pages 289-299 in Richard I. Ford, ed. The nature and status of ethnobotany. Anthropological Papers No. 67, Museum of Anthropology, University of Michigan, Ann Arbor. 